\title{
Interdisciplinary Approach for Salvaging a Carious Multirooted Teeth: A Case Report
}

\section{RAJESH KASHYAP SHANKER', VINO TITO V KURIEN², NIMA SYAM³ ${ }^{3}$, HEGDE SHASHIKANTH ${ }^{4}$, MAIYA ARUN KUMAR 5}

Hemisection denotes sectioning of root with its accompanying crown portion of molars. The outcomes are predictable and success rates are high. In this case report a 29 year old male patient with severe class-III furcation involvement of mandibular molar, which was treated with hemisection and restoration followed by fixed prosthodontic prosthesis.

KEYWORDS: Hemisection, Furcation, Carious, Multirooted, Teeth

\section{INTRODUCTION}

Today's dentistry is based on preservation. The desired outcome for any treatment procedure is to preserve the natural, but proper periodontic, prosthodontic and endodontic assessment for appropriate selection of cases is important. ${ }^{1}$

A terminal molar which has extensive decay cannot be taken as abutment and may be unsuitable for restoration. So the treatment options for the above mentioned case are confined to a removal partial denture or a dental implant. ${ }^{2}$ Alternatively a hemisection methodology could make possible if the decay is constrained to one root. ${ }^{3}$ The outcomes are predictable, and success rates are high if certain fundamental contemplations are taken into account. ${ }^{4}$ Hemisection is a procedure in which one root and corresponding crown portion are removed. Appropriate case selection is essential for an interdisciplinary assessment. There are various indications for hemisection. ${ }^{5}$

\section{Periodontal indications}

- Increased bone loss affecting one or more roots and are not amenable to regenerative procedures

- Furcation involvement(class II or class III)

\section{Endodontic indications}

- Failure to treat and fill a root canal

- Iatrogenic factors(root perforation)

- Severe root resorption

- Carious root structure

\section{Prosthetic indications}

- Root proximity

- Root trunk fracture
General contraindications to periodontal surgery

- Systemic factors

- Poor oral hygiene

Factors associated with tooth anatomy

- Fused roots

- Unfavourable tissue architecture

\section{Endodontic factors}

- Retained roots which cannot be treated endodontically.

- Excessive endodontic instrumentation of retained roots

- Excessive deepening of pulp chamber floor

\section{Restorative factors}

- Internal root decay

- Presence of a cemented post in the remaining root

Strategic considerations ${ }^{6}$

- Consider adjacent teeth available for conventional prosthetic restoration

- Consider removable prosthesis

- Consider implants

This technique represents a sort of conservative management to retain the utmost tooth structure as attainable. ${ }^{7}$ The available bone and soft tissue can be retained with the help of socket preservation after hemisection procedure for better aesthetics and function. ${ }^{8}$

\section{CASE REPORT}

A 29- year old male patient reported to the department with the chief complaint of pain and sensitivity in the 
lower right back tooth region for three months. The patient was systemically healthy and he had a history of smoking since 3 years.

Clinical examination revealed missing right second premolar and a probing depth of $5 \mathrm{~mm}$ was found on the buccal side and $10 \mathrm{~mm}$ on the mesial side along with grade III furcation involvement in the tooth 46 .

Radiographic examination revealed severe vertical bone loss was evident surrounding the mesial root and involving the furcation area and root caries was evident in the mesial root. The bony support of distal root was completely intact. It was decided that the mesial root should be hemisected after completion of endodontic therapy of the tooth. (Figure 1)

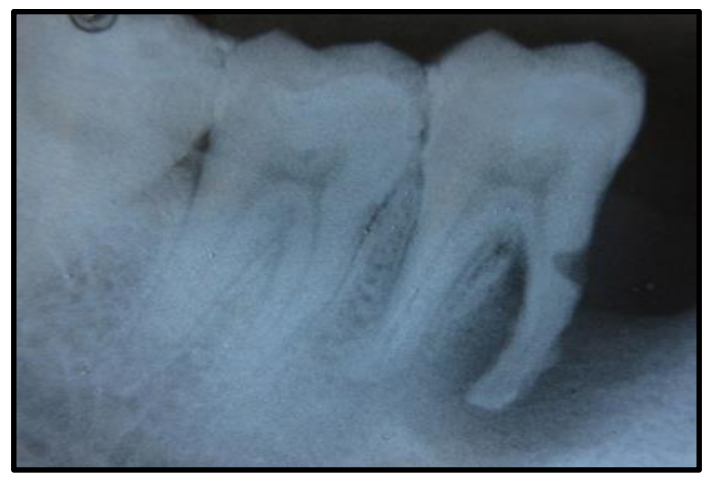

Figure 1. Pre-operative IOPA

\section{Treatment Plan:}

I)Endodontic Phase

II)Periodontic Phase

III)Prosthetic Phase

I) Endodontic Phase: The working length of the canal was determined. Using step back technique the canals were prepared and the canals were obturated with lateral condensation technique. The root canal chamber was filled with composite resin to retain a good seal and permit the interproximal area to be rightly contoured during surgical separation. Reviewing of the patient was done after 15 days and hemisection procedure was carried out. (Figure 2 \& 3 )

II)Periodontic Phase: Under local anesthesia, full thickness flap was reflected after giving a crevicular incision from first the premolar to the second molar and vertical incision was given bilaterally along the line angles of the tooth. After reflection, the bony defect along the distal root was clearly visible. All

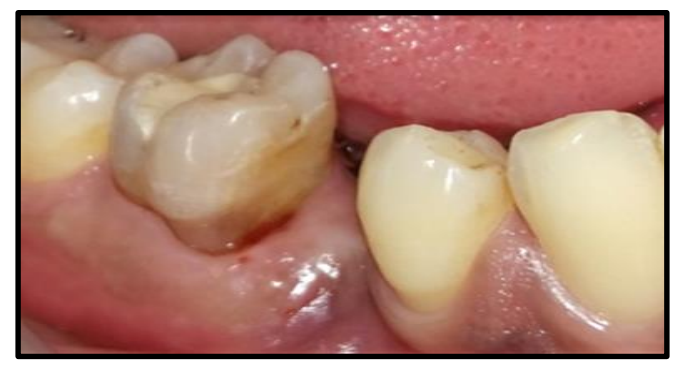

Figure 2. The Tooth after Root Canal Treatment

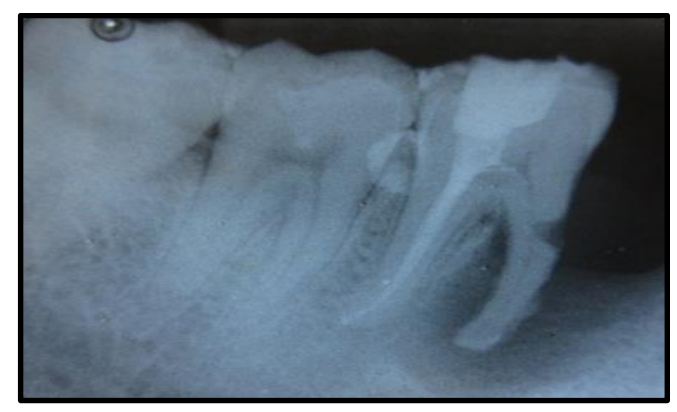

Figure 3. IOPA after Root Canal Treatment

chronic inflammatory tissue was removed with the curette. The resection was done by using vertical cut(towards the bifurcation region) method using a tapered fissured bur using adequate coolant.

The separation of the hemisected portion was confirmed by passing a periodontal probe (Figure 4). The mesial root was extracted. The socket was irrigated with sterile saline to remove bony chips and debris. The remaining portion of the tooth structure(distal) was contoured to remove any ledges or sharp spicules, for proper maintenance oral hygiene.

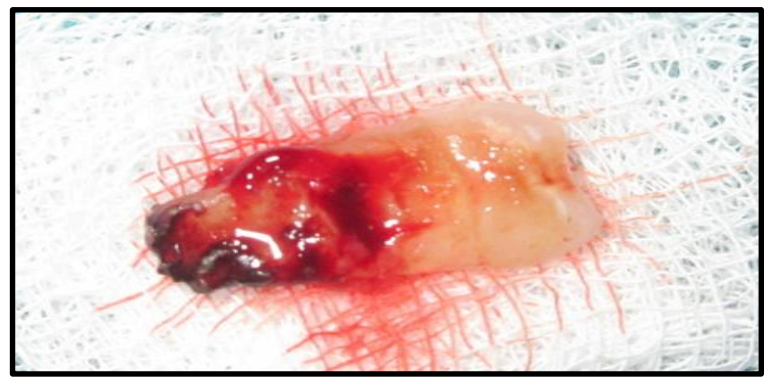

Figure 4. Hemisected mesial root

The extraction site was irrigated with saline and debrided. The flap was then repositioned and sutured with 4/o black braided silk sutures. The occlusal table 
was minimized to reduce the occlusal stress and to redirect the forces along the long axis of the distal root. (Figure 5) Suture removal was done after 7 days and the healing was found to be satisfactory and intraoral periapical radiograph was taken. (Figure $6 \& 7$ ) The patient was recalled after two months for the prosthetic phase.

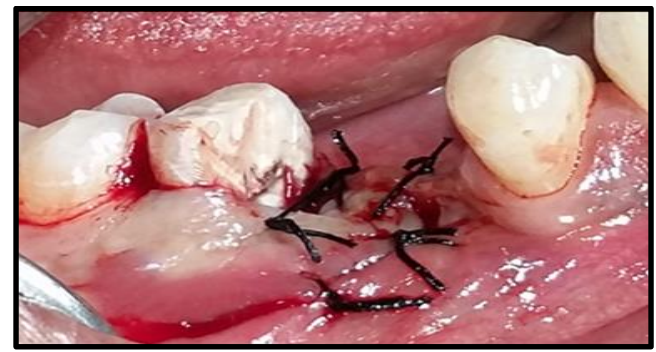

Figure 5. Sutures Placed After Hemisection

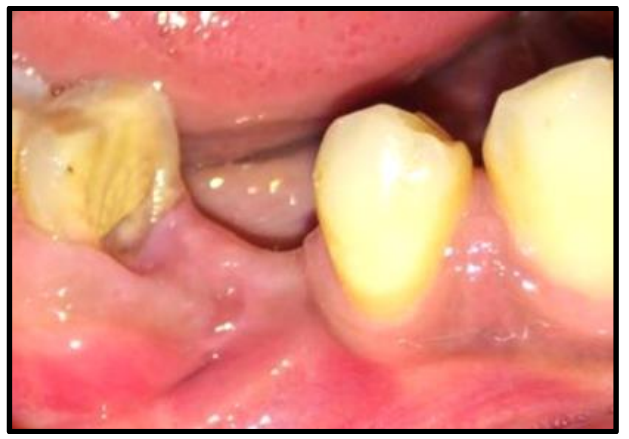

Figure 6. Post-operative picture after 7 days of hemisection

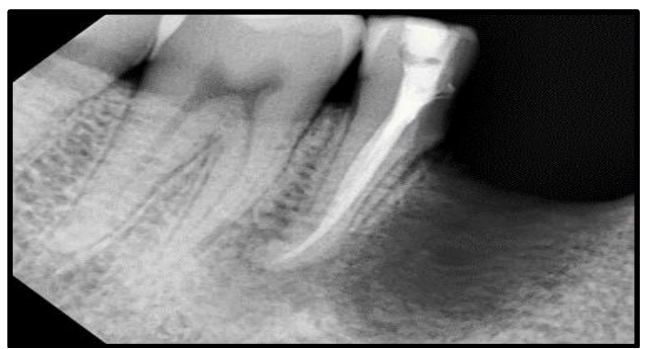

Figure 7. Radiograph Showing Retained Distal Portion

III)Prosthodontic Phase: After healing of the tissues, fixed bridge (porcelain fused) involving retained distal half and mandibular second molar was given. To enhance the oral hygiene maintenance modified ridge lap pontic design was selected. (Figure 8 \& 9)

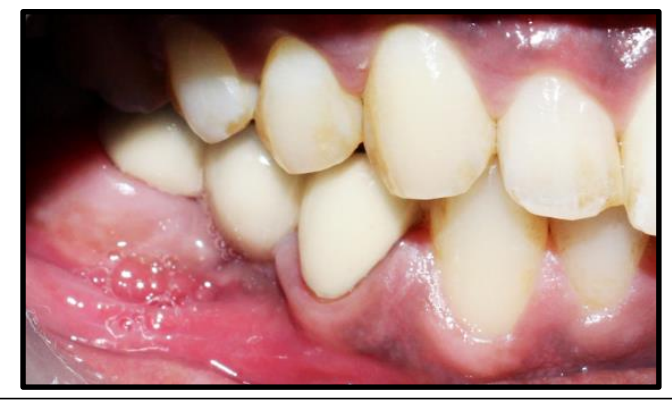

Figure 8. The Treated Tooth After bridge cementation

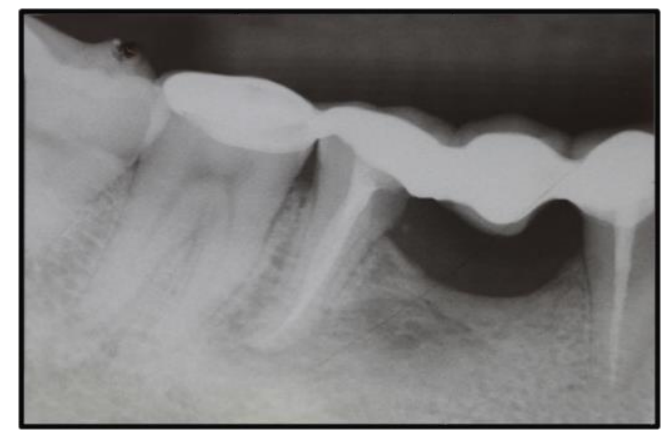

Figure 9. Radiograph After Bridge Cementation(3 Months Post Surgery)

\section{DISCUSSION}

The clinician's call to settle on one treatment set up over another when confronted with a Class III Furcation involvement of a mandibular molar is influenced by many factors. These may be enumerated in three areas:

1. Local factors: The local factors include the position and the anatomy of the tooth in the arch, plaque, calculus, attachment loss, occlusal relationship and the strategic value of the teeth.(retension or removal)

2. Patient factors: The patient factors are the overall systemic health, host bacterial resistance, ability to maintain oral hygiene, time consuming and cost factor.

3. Clinician factors: The clinical factors include diagnostic approach and treatment skills of the clinician, awareness of therapeutic options and clinical acuity or skill in providing service.

Hemisection has been widely used to retain maximum tooth structure possible which is associated with furcation involvement. However, there are a few 
disadvantages associated with the procedure.

Firstly, as with any surgical procedure the patient experiences pain and anxiety. Secondly the hemisected site or the reshaped root surfaces are more liable to caries. Thirdly, if the endodontic treatment plan fails for any reason, subsequently it will cause failure of hemisection procedure. After hemisection one of the roots of multirooted teeth has lost the support to function independently, so the tooth requires a permanent restorative treatment plan to serve as a bridge.

The endodontic treatment can also cause periodontal destruction due to defective margins of the restoration. 9 Another cause for periodontal destruction is trauma from occlusion. It is mainly due to improperly shaped occlusal contact resulting in failure of hemisection. ${ }^{10}$

The factors in the high success rates observed with hemisection therapy are: i)The smaller size of occlusal tables, ii) Under-contouring of the embrasure spaces and iii) Ensuring that the crown margin enclosing the furcation $^{11}$

Hemisection can be considered as a successful alternative to tooth extraction and implant therapy. ${ }^{9}$ The change in discrepancy in success and failure expressed by different authors is a reflection that hemisection is a technique sensitive procedure. One ought to be careful throughout the tactic of case selection, and endodontic periodontic, restorative and maintenance therapies. ${ }^{12}$

\section{CONCLUSION}

With recent clarification in interdisciplinary approach(endodontics, periodontics and restorative dentistry), hemisection has received recognition for managing a hopeless tooth. The treatment execution of hemisection is one way to aid the salvaging of mandibular molars with advanced furcation

Source of support: Nil, Conflict of interest: None declared involvement. Proper case selection enhances the therapeutic success.

\section{REFERENCES}

1. DeSanctis M, Murphy KG. The role of resective periodontal surgery in the treatment of furcation defects. Periodontol 2000 2000;22:154-68.

2. Koka S. Is an implant-supported restoration better than a fixed partial denture to replace single missing teeth? Compend Contin Educ Dent 2006;27(3):158-61. 3. Kost WJ, Stakiw JE. Root amputation and hemisection. J Can Dent Assoc 1991; 57(1):42-5.

4. Kurtzman GM, Silverstein LH, Shatz PC. Hemisection as an alternative treatment for vertically fractured mandibular molars. Compend Contin Educ Dent 2006; 27(2):126-9.

5. Basaraba N. Root amputation and tooth hemisection. Dent Clin North Am 1969;13:121-32.

6. Agrawal VS, Agrawal IS, Kapoor S. Hemisection: Tooth savior maneuver after iatrogenic complication. Int J Health Allied Sci 2015;4:185-7.

7. Agrawal VS, Kapoor S, Shah NC. An innovative approach for treating vertically fractured mandibular molar - Hemisection with socket preservation. J Interdiscip Dent 2012;2:141-3.

8.Bhutada G; Hemisection as a Treatment Option: A Case Report;Indian Journal of Dental Research and Review 2012; 87-90.

9. Sunitha VR, Emmadi P, Namasivayam A, Thyegarajan A, Rajaraman V. The periodontal endodontic continuum: A review. J Conserv Dent. 2008; 11(2):54-62.

10. Mittal S, Kumar T, Bansal R, Kaur D. Hemisection as an alternative treatment for decayed multirooted tooth. Indian Journal Of Dental Sciences. 2010;1(2):89.

11. Behl AB. Hemisection of a multirooted tooth-A case report. Open Access Sci Rep. 2012;1:1-3.

12. Joshipura V. Hemisection-A relevant, practical and successful treatment option. J Int Oral Health. 2011;3(6):43-8.

Cite this article as:

Rajesh KS, Vino Tito VK, Nima S, Hegde S, Arun Kumar MS. Interdisciplinary

approach for Salvaging a Carious Multirooted Teeth: A Case Report. Int Healthc Res J. 2018;2(10):246-249. doi: 10.26440/ihrj.v2i10.183

\section{AUTHOR AFFILIATIONS:}

Professor, Department Of Periodontology

*MDS Post Graduate Student, Department of Periodontology (Corresponding Author)

MDS Post Graduate Student, Department Of Conservative Dentistry

Professor \& Head of Department, Department Of Periodontology

Professor, Department Of Periodontology

Yenepoya Dental College, Deralakatte, Mangalore, India 575018 